\title{
Eficiência Nutricional de Híbridos de Sorgo Granífero ao Fósforo Avaliados sob Diferentes Condições Ambientais
}

Fabricio Rodrigues, Mylla C. Ribeiro, Felipe R. Costa, Leandro F. Damaso, Jéssica S. Pacheco, Daiane M. Duarte \& Cleiton G. S. Benett

O objetivo deste trabalho foi avaliar a eficiência nutricional de dez híbridos de sorgo granífero a doses crescentes de fósforo, em vaso e campo, utilizando a biomassa da planta para comparar a eficiência da seleção, aliados ao ambiente. Existe diferença significativa entre as fontes de variação híbridos e doses, entretanto, não ocorreu para a interação híbridos x doses, impossibilitando a seleção de híbridos eficientes e responsivos, utilizando a biomassa. A correlação fenotípica denota que as plantas respondem fisiologicamente da mesma forma, em vaso e em campo, sendo confirmados pela correlação ambiental, no qual possuíram valores expressivos e significativos.

Palavras Chaves: estresse; biomassa; correlação ambiental.

The objective of this study was to evaluate the nutritional efficiency of ten sorghum hybrid, in increasing levels of phosphorus, vase and field, using plant biomass to compare the efficiency of selection, combined with the environment. There is a significant difference between the sources of variation hybrids and levels, however, the interaction hybrid $\mathrm{x}$ levels not was significant, thus precluding the selection of efficient and responsive hybrid, using biomass. The phenotypic correlation indicates that plants respond physiologically similarly, in the vase and field, confirmed by environmental correlation, being significant and expressive values.

Key words: stress; biomass; environmental correlation. 


\section{Introdução}

A produção mundial de sorgo, para a safra 2012/13, está estimada em 59,2 milhões de toneladas, 8,4\% acima dos 54,6 milhões de toneladas alcançadas na safra 2011/12. Entretanto, mesmo com esse aumento na safra, ainda é considerada baixa, pois, ao analisar o período compreendido entre 2008 a 2013, a produção mundial recorde foi de 66,0 milhões de toneladas, alcançada na safra 2007/08. Além disso, observa-se que a produção mundial, na safra 2012/13, ainda é $2 \%$ inferior à produção média dos últimos cinco anos ${ }^{1}$.

No Brasil, o sorgo é cultivado em todas as regiões do país, todavia, a produção nacional concentra-se nos Estados de Goiás, Minas Gerais e Mato Grosso, juntos, produziram, na safra 2011/12, 1,7 milhão de tonelada, sendo o estado do Goiás o maior produtor, com 999 mil toneladas ${ }^{1}$. Dentre os principais fatores responsáveis pela baixa produtividade, nas áreas destinadas à produção dessas plantas, destacam-se as precipitações irregulares, a fertilidade do solo e as baixas aplicações de fertilizantes ${ }^{2}$, em que normalmente o sorgo é utilizado, visando ao aproveitamento da adubação do plantio anterior e que pouco do que foi extraído do solo, é reposto.

Os solos brasileiros são carentes de fósforo $(\mathrm{P})$, em consequência do material de origem e da forte interação do fósforo com o solo, em que menos de $0,1 \%$ encontra-se em solução, logo, a aplicação de P em doses elevadas em solos do cerrado é justificada pela intensa fixação desse elemento, ocasionando baixo conteúdo de fósforo disponível no solo ${ }^{3}$. Além disso, o excesso causa aumento no custo de produção e sem retorno econômico, nos casos em que os genótipos possuem baixa capacidade em usar o fósforo adsorvido ao solo. Recentemente, um estudo chinês, realizado com dados de 1980 a 2005, comprovou que grande parte do nitrogênio e do fósforo aplicado pela agricultura, foi perdida e que não contribui em nada para aumentar a produção chinesa. Como consequência, causou contaminação dos rios das regiões norte, sul e leste do país ${ }^{4}$ o que torna mais evidente o termo manejo sustentável. O sistema agrícola atual está baseado em patamares de produção, sustentados por expressivas toneladas de adubações e, o melhoramento vegetal de diversas culturas desenvolveu, sob o ideal da revolução verde, ideais contrários ao sistema da sustentabilidade.
A grande expansão do cultivo do sorgo, principalmente em plantios de sucessão a culturas de verão, tem gerado grande demanda por cultivares produtivas e com valor agregado para adaptação às condições predominantes nas regiões de plantios, inclusive para a deficiência de fósforo (P). Entretanto, pouco se conhece da eficiência nutricional dos híbridos de sorgo que estão no mercado atualmente e, além disso, quais seriam mais eficientes em regiões com maior deficiência de fósforo, quais seriam mais responsivos sob doses elevadas e, se fisiologicamente, as plantas apresentariam o mesmo comportamento sob diferentes condições de avaliação.

Diante do exposto, o objetivo deste trabalho foi avaliar a eficiência nutricional de dez híbridos de sorgo granífero a doses crescentes de fósforo, em vaso e campo, utilizando a biomassa da planta para comparar a eficiência da seleção aliada ao ambiente em que os híbridos foram testados.

\section{Materiais e Métodos}

O experimento foi realizado no período da safra convencional 2010/11, na fazenda experimental da Universidade Estadual de Goiás localizada em Ipameri (Latitude 170 43' S, Longitude 480 08' N), a 790 metros de altitude.

Foram utilizados dez híbridos comerciais de sorgo granífero (BRS308, BRS309, BRS310, BRS330, BRS332, AG1040, DKB551, 50A50, AS4610 e 1G282), em três doses de fósforo, sob duas condições de cultivo, em vaso e campo.

\section{EXPERIMENTO EM VASO}

O delineamento experimental utilizado foi o de blocos casualizados, no arranjo fatorial simples, constituído de dez híbridos de sorgo granífero, em três níveis de fósforo, com três repetições. A parcela foi representada por três plantas, em um vaso de 15 litros, o qual foi preenchido com solo de cerrado, proveniente de uma área que apresentava deficiência de P, pela análise química (Tabela 1). Posteriormente, realizou-se a homogeneização do solo, a calagem e, logo após 15 dias, a adubação, conforme a necessidade da planta e visando a uma produtividade média de $12.000 \mathrm{~kg} \mathrm{ha}^{-1}$ para todos os nutrientes, exceto o $\mathrm{P}$. 
As adubações de $\mathrm{P}$ foram 50, 100 e 150\% do necessário para o desenvolvimento adequado da planta, em que a dose $50 \%$ representa somente a metade do necessário para a cultura do sorgo; a dose $100 \%$ representa a adubação ideal e a dose $150 \%$, representa um incremento de $50 \%$, no que é necessário para a cultura. Foram plantadas nove sementes por vaso, sendo o desbaste realizado 15 dias após o plantio, permanecendo apenas três plantas por vaso e irrigados a cada dois.

Os caracteres avaliados foram massa fresca da parte área (MF) e massa seca da parte área (MS), avaliadas aos 90 dias após o plantio, em que as três plantas foram cortadas com o auxílio de uma tesoura de poda e pesadas frescas e, então, colocadas em saquinhos de papel para a pesagem. Logo após, os saquinhos foram colocados na estufa por um período de 72 horas a $70^{\circ} \mathrm{C}$ e, então, pesados para determinação da massa seca.

\section{EXPERIMENTO CAMPO}

O preparo do solo foi realizado de maneira convencional com uma aração e duas gradagens, sendo utilizado um cultivador para abertura dos sulcos. O delineamento experimental utilizado foi o de blocos casualizados, no arranjo fatorial simples, com dez híbridos de sorgo granífero, em três níveis de $P$, com três repetições, em que cada parcela era representada por uma linha de seis metros. O desbaste foi realizado manualmente, quando as plantas apresentavam-se com três a quatro folhas totalmente expandidas, deixando-se cinco plantas por metro, sendo irrigado a cada dois dias.

A adubação de plantio e cobertura, assim como a calagem, foi realizada a partir da análise de solo, adotando-se as doses de 50, 100 e $150 \%$ de P, ou seja, metade do que seria recomendado para a cultura, adubação adequada e 50\%, a mais, do que seria recomendado para a cultura do sorgo, respectivamente, somente para fósforo. Para os demais nutrientes, aplicou-se a dose recomendada para a cultura, visando a uma produtividade média de $12.000 \mathrm{~kg} \mathrm{ha}^{-1}$.

As avaliações de campo foram realizadas aos 90 dias, com a extração de três plantas aleatórias de cada parcela e, então, avaliadas quanto à massa fresca da parte aérea (MF) e massa seca da parte aérea (MS), sendo as plantas cortadas com o auxílio de uma tesoura de poda e colocadas em saquinhos de papel para a pesagem. Logo após, os saquinhos foram colocados na estufa por um período de 72 horas a $70^{\circ} \mathrm{C}$ e, posteriormente, pesados para determinação da massa seca.

\section{ANÁLISE DOS DADOS}

A análise dos dados foi realizada no programa estatístico GENES ${ }^{6}$, calculando-se a média e a interação entre os híbridos e as doses, por meio da análise de variância individual e conjunta, utilizando os seguintes modelos matemáticos para análise de variância:

$$
\mathrm{Y}_{\mathrm{ij}}=\mu+\mathrm{g}_{\mathrm{i}}+\mathrm{b}_{\mathrm{j}}+\mathrm{e}_{\mathrm{ij}}(\text { Individual })
$$

em que: $Y_{i j}=$ observação feita na parcela do i-ésimo tratamento no $\mathrm{j}$-ésimo bloco; $\mu=$ média geral; $\mathrm{g}_{\mathrm{i}}=$ efeito do i-ésimo híbrido; $b_{j}=$ efeito do j-ésimo bloco; $e_{i j}=$ efeito dos fatores não controlados na parcela que recebeu o i-ésimo híbrido no j-ésimo bloco.

$$
\mathrm{Y}_{\mathrm{ij}} \mathrm{k}=\mu+\mathrm{g}_{\mathrm{i}}+\mathrm{a}_{\mathrm{j}}+\mathrm{ga}_{\mathrm{ij}}+\mathrm{b}_{\mathrm{k}} / \mathrm{a}_{\mathrm{j}}+\mathrm{e}_{\mathrm{ij}} \mathrm{k} \text { (Conjunta) }
$$

em que: $Y_{\mathrm{ij}} \mathrm{k}=$ observação feita na parcela do i-ésimo híbrido no j-ésimo bloco; $\mu$ = média geral; $g_{i}=$ efeito do i-ésimo genótipo; $a_{j}=$ efeito da j-ésimo dose; $g_{\mathrm{ij}}=$ efeito da interação do i-ésimo híbrido com a j-ésimo dose; $\mathrm{b}_{\mathrm{k}} \mathrm{a}_{\mathrm{j}}=$ efeito do $\mathrm{k}$-ésimo bloco dentro da j-ésimo dose; $\mathrm{e}_{\mathrm{ij}} \mathrm{k}=$ efeito dos fatores não controlados na parcela que recebeu o i-ésimo genótio no j-ésimo ambiente dentro do k-ésimo bloco. Posteriormente, estimados os coeficientes da correlação fenotípica, ambiental e a herdabilidade no sentido amplo, entre os caracteres, utilizando as expressões apresentadas por Cruz e Regazzi ${ }^{6}$.

\section{Resultados e Discussão}

O resumo da análise de variância conjunta, para todos os caracteres avaliados, está apresentada na Tabela 2. Paras as fontes de variação híbridos e, também, doses, houve diferença significativa a 1 e $5 \%$ para todas as variáveis analisadas, independente da condição ambiental em que a biomassa foi avaliada. Entretanto, a fonte de variação híbridos $\mathrm{x}$ doses, não apresentou diferença significativa $(\mathrm{P} \leq 0,05)$, para todos os caracteres avaliados. Isso indica que os híbridos testados apresentaram o mesmo comportamento nas diferentes doses de fósforo (Tabela 2). 
Tabela 1. Principais atributos químicos do solo (0-20 cm de profundidade), 30 dias antes da aplicação dos fertilizantes e do calcário, no sulco de semeadura. Ipameri, GO, 2013.

\begin{tabular}{|c|c|c|c|c|c|c|c|c|c|c|}
\hline \multirow{2}{*}{ Solo } & pH & M.O. & Presina & $\mathrm{H}+\mathrm{Al}$ & $\mathbf{K}$ & $\mathbf{C a}$ & Mg & SB & CTC & V\% \\
\hline & $(\mathrm{CaCl} 2)$ & $(\mathrm{g} \mathrm{dm}-3)$ & (mg dm-3) & \multicolumn{7}{|c|}{ mmolc dm-3 } \\
\hline $0-20 \mathrm{~cm}$ & 4,3 & 16,2 & 2,4 & 41,8 & 1,5 & 8,5 & 2,8 & 12,8 & 54,6 & 23,4 \\
\hline
\end{tabular}

Para Carvalho $^{7}$, essa falta de interação não é esperada, quando se trabalha com grupos de cultivares com alta variabilidade genética, havendo diferença entre eles para diversas características morfofisiológicas. Normalmente, os solos das regiões tropicais, além da deficiência generalizada, apresentam alta capacidade de fixação de fosfato (adsorção e precipitação), limitando a produtividade das culturas nessas áreas ${ }^{8}$. Apesar da calagem e da adubação com $50 \%$ a mais de $\mathrm{P}$, as plantas podem ter os mesmos mecanismos de expressão gênica para produção de raiz, dessa forma, o mesmo resultado por não conseguirem acessar o $\mathrm{P}$ disponível no solo. $\mathrm{O}$ contato do íon fosfato nas raízes ocorre, preferencialmente, por difusão, razão pela qual a absorção do nutriente depende do volume de solo explorado pelas raízes ${ }^{9}$.

Tabela 2. Resumo da análise de variância conjunta e estimativa da herdabilidade $\left(\mathrm{h}^{2}\right)$ para os caracteres massa fresca da parte área (MFPA) e massa seca da parte área (MSPA), avaliados em vaso e campo, sob diferentes doses de fósforo no solo. Universidade Estadual de Goiás, Ipameri, GO, 2013.

\begin{tabular}{|c|c|c|c|c|c|}
\hline \multirow{2}{*}{ FV } & \multicolumn{5}{|c|}{ QM } \\
\cline { 2 - 6 } & $\mathbf{G L}$ & $\mathbf{M F}^{\mathbf{1}}$ & $\mathbf{M S}^{\mathbf{1}}$ & $\mathbf{M F}^{\mathbf{2}}$ & $\mathbf{M}^{\mathbf{s} 2}$ \\
\hline Híbridos & 9 & $5271,73^{* *}$ & $271,35^{* *}$ & $108885,51^{* *}$ & $47141,78^{* *}$ \\
\hline Doses & 2 & $13085,46^{* *}$ & $238,68^{*}$ & $434333,22^{* *}$ & $159753,18^{* *}$ \\
\hline $\begin{array}{c}\text { Híbridos } \\
\mathbf{x} \text { doses }\end{array}$ & 18 & $1096,27^{\text {n.s. }}$ & $88,19^{\text {n.s. }}$ & $19295,03^{\text {n.s. }}$ & $9740,91^{\text {n.s. }}$ \\
\hline Repetição & 2 & 1612,33 & 86,44 & 53112,10 & 7943,20 \\
\hline Erro & 58 & 830,70 & 51,25 & 22471,83 & 9547,44 \\
\hline CV (\%) & - & 25,34 & 18,97 & 30,02 & 32,87 \\
\hline CVg (\%) & - & 20,49 & 13,40 & 20,49 & 28,35 \\
\hline $\mathbf{h}^{\text {2/Dose 50\% }}$ & - & 36,66 & 31,43 & 72,26 & 64,71 \\
\hline $\mathbf{h}^{\text {2/Dose 100\% }}$ & - & 70,43 & 87,56 & 63,80 & 56,25 \\
\hline $\mathbf{h}^{2 / \text { Dose 150\% }}$ & - & 76,24 & 73,97 & 14,62 & 4,18 \\
\hline
\end{tabular}

* e ** significativo a 5 e $1 \%$ de probabilidade, pelo teste $\mathrm{F}$; ns - não significativo;

${ }^{1} \mathrm{e}^{2}-$ Biomassa avaliada sob condições de vaso e campo, respectivamente.
O coeficiente de variação $(\mathrm{CV} \%)$ representa a precisão experimental, nota-se que os maiores valores foram apresentados pelas variáveis analisadas a campo, entretanto, os valores são considerados similares aos citados na literatura. Percebe-se que, quando os estudos estão relacionados à eficiência nutricional ao $\mathrm{P}$, em diferentes culturas, por exemplo, sorgo ${ }^{10,11}$, milho $^{12} \mathrm{e}$ pimentão $0^{13}$ ou sob condições de outros estresses, como hídrico ${ }^{14}$, esses valores apresentam alta variação entre as doses testadas, características analisadas, genótipos e a safra em questão.

Testando a resposta da cultura do sorgo granífero, na safrinha, em nível de campo, submetidos a diferentes doses e fontes de nitrogênio em cobertura, Goes ${ }^{15}$ e colaboradores obtiveram valores bem abaixo para matéria seca $(1,64 \%)$, tal êxito foi alcançado por apresentar uma repetição a mais e, além disso, uma área útil três vezes maior do que a apresentada neste experimento.

No caso de competição de plantas por nutrientes, o $\mathrm{CV} \%$ encontrado é mais condizente com o de trabalhos de eficiência nutricional, visto que as plantas necessitam aprofundar suas raízes em busca de nutrientes. Lopes ${ }^{16}$, estudando o comportamento de plantas de sorgo a diferentes espaçamentos encontrou $\mathrm{CV} \%$ variando de 15,1 a $37,3 \%$, sendo a média em torno de $25 \%$, indicando que a precisão experimental também está ligada ao estande final, no qual a menor área útil para a planta aumenta a relação de deficiência e variação entre os dados. É conveniente, em experimentos dessa natureza, a utilização de parcelas experimentais maiores, com maior número de fileiras e, também, um maior número de repetições, a fim de alcançar uma precisão maior e obter êxito com a seleção de cultivares eficientes e responsivos ao $P$.

Os valores dos coeficientes de variação genética $(\mathrm{CVg})$ refletem a boa variação entre os híbridos, apesar de ser mais relevante no caráter MS, com valor de 28,35\%, quando avaliado a campo (Tabela 2). $\mathrm{O} \mathrm{CV}_{\mathrm{g}}$ representa 
a razão, expressa em porcentagem, entre o desvio do padrão genético e a média das cultivares, indicando existir diversidade entre os híbridos testados, apesar de serem provenientes, em sua maioria, do Programa de Melhoramento da Embrapa Milho e Sorgo.

A herdabilidade $\left(\mathrm{h}^{2}\right)$ permite antever a possibilidade de sucesso com a seleção, uma vez que ela reflete a proporção da variação fenotípica que pode ser herdada. Verifica-se que o ganho com a seleção será mais eficiente, se a seleção for realizada em vaso, nas doses $100 \%$ e $150 \%$, tanto para MF quanto para MSPA, com valores variando de 70,43 a $87,56 \%$, similares a outros trabalhos ${ }^{17,18}$. Percebe-se que, se a seleção for visando híbridos mais responsivos, a análise deveria ser feita utilizando vasos. Entretanto, quando o interesse do programa for a eficiência dos híbridos de sorgo, as análises deveriam ser realizadas a campo, dessa forma, obtendo o máximo de êxito, de acordo com a Tabela 2.

Detecta-se que os híbridos de melhor desempenho para MF e MS, simultaneamente, sob condições de vaso, foram os híbridos AG1040, BRS 330, BRS 332 e o DKB 551 (Tabela 3). Em contrapartida, o híbrido de melhor desempenho, sob condições de campo, simultaneamente, para as duas variáveis analisadas, foi somente o híbrido $1 \mathrm{G} 282$. Indicando que a seleção deve menos criteriosa quando for realizada a campo e com um maior número de variáveis para confirmar o desempenho dos genótipos testados. É conveniente salientar que as folhas e colmos (biomassa da parte aérea) não sofreram quaisquer alterações nas diferentes doses, indicando que esses caracteres podem auxiliar na seleção, mas, que prejudicariam o programa de melhoramento, se utilizados sem qualquer outro critério, como a produtividade, para a avaliação da eficiência e resposta.

A correlação tem importância no melhoramento de plantas porque quantifica o grau de associação genético e não-genético entre dois ou mais caracteres. A eficiência da seleção de um caráter pode ser aumentada com a utilização de caracteres agronômicos correlacionados ${ }^{19}$. Assim, se existir correlação entre caracteres avaliados em vaso, com caracteres avaliados em campo, isso reduziria o tempo e a área que são gastos na avaliação de um grande número de híbridos, testados em campo. Outro ponto a se considerar é que estas associações quantificam a possibilidade de ganhos indiretos por seleção em caracteres correlacionados.
Tabela 3. Médias dos caracteres massa fresca da parte área (MF) e massa seca da parte área (MS), avaliados em vaso e campo, sob diferentes doses de fósforo no solo. Universidade Estadual de Goiás, Ipameri, GO, 2013.

\begin{tabular}{|c|c|c|c|c|}
\hline HÍBRIDOS & MF $^{\mathbf{1}}$ & $\mathbf{M S}^{\mathbf{1}}$ & $\mathbf{M F}^{\mathbf{2}}$ & $\mathbf{M S}^{\mathbf{2}}$ \\
\hline $\mathbf{1 G 2 8 2}$ & $92,38 \mathrm{~b}$ & $29,76 \mathrm{c}$ & $709,09 \mathrm{a}$ & $384,97 \mathrm{a}$ \\
\hline $\mathbf{5 0 A 5 0}$ & $90,87 \mathrm{~b}$ & $31,42 \mathrm{c}$ & $443,01 \mathrm{c}$ & $175,66 \mathrm{~b}$ \\
\hline AG1040 & $146,54 \mathrm{a}$ & $43,31 \mathrm{a}$ & $427,01 \mathrm{c}$ & $212,96 \mathrm{~b}$ \\
\hline AS4610 & $123,38 \mathrm{a}$ & $36,27 \mathrm{~b}$ & $574,19 \mathrm{~b}$ & $297,98 \mathrm{a}$ \\
\hline BRS308 & $88,01 \mathrm{~b}$ & $36,83 \mathrm{~b}$ & $414,06 \mathrm{c}$ & $170,69 \mathrm{~b}$ \\
\hline BRS309 & $79,44 \mathrm{~b}$ & $30,16 \mathrm{c}$ & $379,09 \mathrm{c}$ & $190,59 \mathrm{~b}$ \\
\hline BRS310 & $86,10 \mathrm{~b}$ & $36,06 \mathrm{~b}$ & $324,57 \mathrm{c}$ & $131,58 \mathrm{~b}$ \\
\hline BRS330 & $120,28 \mathrm{a}$ & $40,17 \mathrm{a}$ & $497,90 \mathrm{~b}$ & $232,56 \mathrm{~b}$ \\
\hline BRS332 & $132,57 \mathrm{a}$ & $45,72 \mathrm{a}$ & $526,20 \mathrm{~b}$ & $228,86 \mathrm{~b}$ \\
\hline DKB551 & $132,01 \mathrm{a}$ & $40,68 \mathrm{a}$ & $527,56 \mathrm{~b}$ & $253,24 \mathrm{~b}$ \\
\hline Médias & $\mathbf{1 0 9 , 1 6}$ & $\mathbf{3 7 , 0 4}$ & $\mathbf{4 8 2 , 2 7}$ & $\mathbf{2 2 7 , 9 1}$ \\
\hline
\end{tabular}

Médias seguidas pela mesma letra na vertical, não diferem entre si pelo teste de Scott Knott a $5 \%$ de probabilidade;

${ }^{1} \mathrm{e}^{2}-$ Biomassa avaliada sob condições de vaso e campo, respectivamente.

Observa-se, conforme a Tabela 4, que a maioria das correlações foram significativas, exceto para MF, obtida no experimento em campo, na dose $50 \%$ e a MF na dose $100 \%$ obtida em vaso e, também, entre a MF na dose $100 \%$ avaliada em campo e a MF na dose $50 \%$ avaliada em vaso.

Isto sugere a possibilidade de avaliação de híbridos, em vaso, com a possibilidade dos resultados serem extrapolados para campo, justificando que é possível a avaliação prévia em vaso e, posterior avaliação em campo. O resultado esperado seria que as correlações fossem altas, tanto para MF quanto para MS, quando estivessem sob o mesmo estresse ou sob a mesma condição de adubação, neste caso, confirmados pelos altos valores obtidos na diagonal da Tabela 4 e 5 .

A correlação ambiental indica que se os caracteres envolvidos são afetados pela variância ambiental de modo análogo, ou seja, se a estimativa da correlação ambiental é alta e positiva, depreende-se que os dois caracteres, que são influenciados pela variação ambiental, são afetados igualmente pelos caracteres. Se a situação ocorre em sentido contrário (correlação negativa), isto é, em direção contrária, os ambientes afetam de maneira contraria os caracteres em questão. 
Tabela 4. Correlação fenotípica entre os caracteres de massa fresca da parte área das plantas, avaliados em vaso na dose 50\% (MF50 $\left.{ }^{1}\right), 100 \%$ $\left(\mathrm{MF} 100^{1}\right)$ e $150 \%\left(\mathrm{MF} 150^{1}\right)$ com a massa fresca avaliada em campo na dose $50 \%\left(\mathrm{MF}^{2} 0^{2}\right), 100 \%\left(\mathrm{MF} 100^{2}\right)$ e $150 \%\left(\mathrm{MF} 150^{2}\right)$. Ipameri, GO, 2013.

\begin{tabular}{|c|c|c|c|}
\hline Caracteres & MF50 ${ }^{1}$ & $\mathrm{MF} 100^{1}$ & MF1501 \\
\hline${\mathrm{MF} 50^{2}}^{2}$ & $89,8 * *$ & 26,8 n.s. & $61,4^{*}$ \\
\hline MF100 & $52,9^{\text {n.s. }}$ & $97,7 * *$ & $69,7 * *$ \\
\hline $\mathrm{MF} 150^{2}$ & $60,4^{*}$ & $61,3 *$ & $97,9 * *$ \\
\hline
\end{tabular}

*,** - significativo a 1 e $5 \%$ pelo teste t, n.s. - não significativo; 1 e 2 - Biomassa avaliada sob condições de vaso e campo, respectivamente.

Tabela 5. Correlação fenotípica entre os caracteres de massa seca da parte área das plantas, avaliados em vaso na dose $50 \%\left(\mathrm{MS}^{1} 0^{1}\right), 100 \%$ $\left(\mathrm{MS}_{100}\right)$ e $150 \%\left(\mathrm{MS} 150^{1}\right)$ com a massa fresca avaliada em campo na dose $50 \%\left(\mathrm{MS}^{2} 0^{2}\right), 100 \%\left(\mathrm{MS}_{100^{2}}\right)$ e $150 \%\left(\mathrm{MS} 150^{2}\right)$. Ipameri, GO, 2013

\begin{tabular}{|c|c|c|c|}
\hline Caracteres & ${\mathrm{MS} 50^{1}}^{1}$ & $\mathrm{MS} 100^{1}$ & $\mathrm{MS} 150^{1}$ \\
\hline $\mathrm{MS}^{2} 0^{2}$ & $95,2^{* *}$ & $53,7^{\text {n.s. }}$ & $0,9^{\text {n.s. }}$ \\
\hline $\mathrm{MS} 100^{2}$ & $67,7^{*}$ & $90,1^{* *}$ & $58,4^{*}$ \\
\hline $\mathrm{MS} 150^{2}$ & $20,2^{\text {n.s. }}$ & $46,2^{\text {n.s. }}$ & $95,5^{* *}$ \\
\hline
\end{tabular}

*** - significativo a 1 e $5 \%$ pelo teste $\mathrm{t}$, n.s. - não significativo $;{ }^{1} \mathrm{e}^{2}-$ Biomassa avaliada sob condições de vaso e campo, respectivamente.

Nota-se que a correlação ambiental apresentou valores altos e significativos na diagonal (Tabela 6 e 7), demonstrando que o comportamento dos híbridos para MF e MS, sob estresses ou sob doses elevadas de fósforo, responderam da mesma forma nas diferentes condições testadas. E, que a correlação fosse não significativa, se possível, quando a comparação estivesse sendo realizada entre as doses $50 \%$ e a dose $150 \%$, ou seja, ambientes contrários de avaliação da eficiência nutricional. Percebe-se que apesar de existir correlação positiva e significativa entre MF50, em vaso, com MF150, em campo, o resultado é considerado baixa amplitude.

Tabela 6. Correlação ambiental entre os caracteres de massa fresca da parte área das plantas, avaliados em vaso na dose 50\% (MF501), 100\% (MF1001) e 150\% (MF1501) com a massa fresca avaliada em campo na dose $50 \%$ (MF502), 100\% (MF1002) e 150\% (MF1502). Ipameri, GO, 2013

\begin{tabular}{|c|c|c|c|}
\hline Caracteres & MF50 ${ }^{1}$ & MF100 1 & MF $150^{1}$ \\
\hline $\mathrm{MF}^{2} 0^{2}$ & $92,1 * *$ & $12,1^{\text {n.s. }}$ & $57,3^{* *}$ \\
\hline $\mathrm{MF} 100^{2}$ & $23,0^{\text {n.s. }}$ & $88,9 * *$ & $27,6^{\text {n.s. }}$ \\
\hline $\mathrm{MF} 150^{2}$ & $32,5^{\text {n.s. }}$ & $0,13^{\text {n.s. }}$ & $97,4 * *$ \\
\hline
\end{tabular}

Tabela 7. Correlação ambiental entre os caracteres de massa seca da parte área das plantas, avaliados em vaso nas dose $50 \%\left(\mathrm{MS}_{50}{ }^{1}\right), 100 \%$ $\left(\mathrm{MS}_{100^{1}}\right)$ e $150 \%\left(\mathrm{MS}^{2} 50^{1}\right)$ com a massa seca avaliada em campo, nas dose $50 \%\left(\mathrm{MS}^{2}\right), 100 \%\left(\mathrm{MS}_{100^{2}}\right)$ e $150 \%\left(\mathrm{MS}^{2} 50^{2}\right)$. Ipameri, GO, 2013.

\begin{tabular}{|c|c|c|c|}
\hline Caracteres & $\mathrm{MS}^{2} 0^{1}$ & $\mathrm{MS} 100^{1}$ & MS150 1 \\
\hline $\mathrm{MS}^{2} 0^{2}$ & $87,5^{* *}$ & $0,76^{\text {n.s. }}$ & $28,0^{\text {n.s. }}$ \\
\hline $\mathrm{MS} 100^{2}$ & $21,9^{\text {n.s. }}$ & $15,6^{\text {n.s. }}$ & $27,6^{\text {n.s. }}$ \\
\hline $\mathrm{MS} 150^{2}$ & $16,4^{\text {n.s. }}$ & $0,08^{\text {n.s. }}$ & $95,6^{* *}$ \\
\hline
\end{tabular}

A correlação fenotípica denota que as plantas respondem fisiologicamente da mesma forma, em vaso e em campo, sendo, então, comprovados pela correlação ambiental dos caracteres MF e MS, reforçando ainda mais a possibilidade de se fazer seleção de genótipos superiores em vaso e, posteriormente, testá-los em campo, com a possibilidade de obter bons resultados em relação à eficiência nutricional em sorgo ao fósforo.

\section{Conclusão}

Existe diferença significativa entre os híbridos e as doses testadas, entretanto, não ocorreu interação entre os híbridos x doses, impossibilitando a seleção de híbridos eficientes e responsivos, utilizando a biomassa.

A correlação fenotípica denota que as plantas respondem fisiologicamente da mesma forma, em vaso e em campo, sendo confirmados pela correlação ambiental, no qual possuíram valores expressivos e significativos.

\section{Referências}

1. Companhia Nacional de Abastecimento. Produção brasileira de sorgo granífero. Disponível em: $<$ http://www.conab. gov.br/OlalaCMS/uploads/arquivos/12 $09 \begin{array}{lllll}0 & 11 & 16 & 41 & 03\end{array}$ prospeccao_12_13.pdf $>$. Acesso em: 20 julho. 2013.

2. Aguiar, M. S; Moraes, A. V. de C. de; Guimarães, D. P. Sistemas de Produção. Versão Eletrônica, 2007, 3.

3. Ernani, P.R.; Bayer, C.; Maestri, L.Agronomy Journal, 2002, 94, 305 .

4. Ma, L.; Velthof, G. L.; Wang, F. H.; Qin, W.; Zhang, W. F.; Liu, Z.; Zhang, F. S. Science of The Total Environment, 2012, 434,.51.

5. Santos, F. G. dos; Rodrigues, J. A. S.; Schaffert, R. E.; Casela, C. R.; Ferreira, A. da S. Híbrido do sorgo granífero BRS 308, 2007, $4,146$. 
6. Cruz, C.D. Biometria. Editora UFV, 2006, 1, 382.

7. Carvalho, E. V.; Afférri, F. S.; Peluzio, J. M.; Leão, F. F.; Cancellier, L. L.; Dotto, M. A. Bioscience Journal, 2011,. 27, 392.

8. Novais, R. F.; Alvarezv, V. H. ; Barros, N. F.; Fontes, R. L. F. ; Cantarutti, R. B. ; Neves, J. C. L. Sociedade Brasileira de Ciência do Solo, 2007, 1, 1017.

9. Malavolta, E.; Vitti, G.C.; Oliveira, S.A. Piracicaba Potafos, 1997, 2, 319 .

10. Almeida Filho, J. E. D., Tardin, F. D., Souza, S. Â. D.; Godinho, V. D. P. C.; Cardoso, M. J. Revista Brasileira de Milho e Sorgo, 2010, 9,51 .

11. Rodrigues, F. Tese de doutorado em Genética e Melhoramento de plantas, Universidade Federal de Lavras, 2010, 1, 95.

12. Machado, C. T. de T.; Furlani, A. M. C.; Machado, A. T. Bragantia, 2001, 60, 225.

13. Oliveira, V. R.; Casali, V. W. D.; Pereira, P. R. G.; Cruz, C. D.; Pires, N. M. Bragantia, 1999, 58, 125.

14. Ferreira, L. E.; Silva, I. D. F. D.; Souza, E. P. D.; Souza, M. A.; Borchartt, L. Revista Verde, 2012, 7, 249.

15. Goes, R. J.; Rodrigues, R. A. F.; Arf, O.; Arruda, O. G. D.; Vilela, R. G. Revista Brasileira de Milho e Sorgo, 2011, 10, 121.

16. Lopes, S. J.; Brum, B.; Storck, L.; Lúcio, A. D. C.; Silveira, R. da. Toebe, M. Ciência Rural, 2009, 39, 650.

17. Cunha, E. E.; Lima, J. M. P. Revista Brasileira de Zootecnia, 2010, 39, 701 .
18. Kenga, R.; Tenkouano, A.; Gupta, S.C. Alabi, S. O. Euphytica, 2006, 150, 319 .

19. Cruz, C. D.; Regazzi, A. J. Modelos biométricos aplicados ao melhoramento genético, 2001, 2, 390.

\section{Fabricio Rodrigues ${ }^{1 *}$, Mylla C. Ribeiro², Felipe R. Costa ${ }^{2}$, Leandro F. Damaso², Jéssica S. Pacheco², Daiane M. Duarte ${ }^{2} \&$ Cleiton G. S. Benett $^{\prime}$}

\footnotetext{
${ }^{1}$ Universidade Estadual de Goiás, Departamento de Agronomia, Rodovia GO 330, Km 241, Anel Viário, s/n, Setor Universitário, CEP 75780-000, Ipameri-GO, Brasil.

${ }^{2}$ Universidade Estadual de Goiás, Departamento de Agronomia e Produção Vegetal, Rodovia GO 330, Km 241, Anel Viário, s/n, Setor Universitário, CEP 75780-000, Ipameri-GO, Brasil.

*e-mail: fabricio.rodrigues@ueg.br
} 
